\title{
$\beta$-catenin is required in the neural crest and mesencephalon for pituitary gland organogenesis
}

\author{
Shannon W. Davis ${ }^{1 *}$, Amanda H. Mortensen², Jessica L. Keisler', Amanda L. Zacharias ${ }^{3,5}$, Philip J. Gage ${ }^{3}$, \\ Ken-ichi Yamamura ${ }^{4}$ and Sally A. Camper ${ }^{2}$
}

\begin{abstract}
Background: The pituitary gland is a highly vascularized tissue that requires coordinated interactions between the neural ectoderm, oral ectoderm, and head mesenchyme during development for proper physiological function. The interactions between the neural ectoderm and oral ectoderm, especially the role of the pituitary organizer in shaping the pituitary precursor, Rathke's pouch, are well described. However, less is known about the role of head mesenchyme in pituitary organogenesis. The head mesenchyme is derived from definitive mesoderm and neural crest, but the relative contributions of these tissues to the mesenchyme adjacent to the pituitary are not known.

Results: We carried out lineage tracing experiments using two neural crest-specific mouse cre lines, Wnt1-cre and PO-cre, and determined that the head mesenchyme rostral to the pituitary gland is neural crest derived. To assess the role of the neural crest in pituitary development we ablated it, using Wnt1-cre to delete Ctnnb1 ( $\beta$-catenin), which is required for neural crest development. The Wnt1-cre is active in the neural ectoderm, principally in the mesencephalon, but also in the posterior diencephalon. Loss of $\beta$-catenin in this domain causes a rostral shift in the ventral diencephalon, including the pituitary organizer, resulting in pituitary dysmorphology. The neural crest deficient embryos have abnormally dilated pituitary vasculature due to a loss of neural crest derived pericytes.
\end{abstract}

Conclusions: $\beta$-catenin in the Wnt1 expression domain, including the neural crest, plays a critical role in regulation of pituitary gland growth, development, and vascularization.

Keywords: Neural crest, Pituitary gland, Organogenesis, $\beta$-catenin, Vasculature

\section{Background}

In comparison to invertebrate chordates, vertebrates are characterized by an elaborate head with an expanded brain, elaborate sensory organs, and a craniofacial skeleton. These modifications from the ancestral chordate where enabled in part by the appearance of neural crest cells, neurogenic placodes, and muscularized hypomeres, which are derived from definitive mesoderm, in the ancestral vertebrate $[1,2]$. These three tissues, along with the neural ectoderm, interact in diverse ways to form the elaborate head structures of vertebrates, including sensory organs and craniofacial skeletal components $[3,4]$. The

\footnotetext{
*Correspondence: swdavis@mailbox.sc.edu

'Department of Biological Sciences, University of South Carolina, 715 Sumter St. CLS room 401, Columbia, SC 29208, USA

Full list of author information is available at the end of the article
}

pituitary gland also appears with the formation of vertebrates and is partially derived from the adenohypophyseal placode [5]. The contributions of the adenohypophyseal placode to pituitary development are well described $[5,6]$; however, much less is known about neural crest and definitive mesoderm contributions to pituitary organogenesis.

Rathke's pouch, the precursor to the pituitary anterior and intermediate lobes, is surrounded by cranial head mesenchyme and is in close proximity to the rostral end of the notochord and pre-chordal plate, which have important signaling functions in early head development [7]. Chick explant studies demonstrated that co-cultures of the ventral diencephalon and Rathke's pouch could only induce differentiation of corticotropes when mesenchyme was included in the culture [8]. Additionally, 
explants of chick notochord can cause surface ectoderm to invaginate, forming a structure similar to Rathke's pouch [8]. These experiments suggest that chick head mesenchyme plays a role in supporting cell differentiation in the anterior lobe. The permissive mesenchymal signal for anterior lobe cell specification has not been identified. Several secreted factors expressed in mouse pituitary adjacent mesenchyme, including Chordin, Noggin, Nbl1, and Fstl1, are candidates for a mesenchymal signal in pituitary organogenesis [9-11]. Foxd1 is a forkhead domain transcription factor expressed in the pituitary adjacent mesenchyme, and $F o x d 1^{-/-}$mice have increased proliferation of anterior lobe cells and decreased LH $\beta$ expression. These results suggest that Foxd1 may regulate the expression of a mesenchymal signal necessary for pituitary development [12].

The cranial mesenchyme contributes to the hypophyseal portal system, which is a network of blood vessels that surrounds and invades the pituitary gland, enabling delivery of releasing hormones from the hypothalamus to the pituitary anterior lobe and from the pituitary gland to target organs in the body. The head mesenchyme is comprised of both definitive mesoderm, migrating through the primitive streak, and neural crest, which migrates away from the dorsal side of the neural tube and throughout the body [4]. The neural crest forms much of the peripheral nervous system, which is consistent with its ectodermal origin, but within the head it contributes to tissues, such as bones, muscles, and dermis of the skin, which are usually derived from definitive mesoderm [13]. In recognition of the diversity of tissues generated by the neural crest, it is frequently described as a fourth germ layer [14]. The developmental plasticity of the neural crest results from the maintenance of a gene regulatory network, characteristic of pluripotent blastula cells, in the neural crest lineage [15]. The cranial vasculature reflects the dual contributions of definitive mesoderm and neural crest; endothelial cells are derived from definitive mesoderm and the neural crest forms the pericytes and smooth muscle that wrap around and regulate the endothelial cells [16-18]. To define the contributions of head mesenchyme to pituitary organogenesis, we utilized a genetic model to examine neural crest contributions to pituitary gland organogenesis. $\beta$-CATENIN is a key component of canonical Wnt signaling, and loss of $\beta$ catenin in the neural crest lineage is known to cause apoptosis of migrating neural crest cells, leading to severe head malformations [19]. We present here an analysis of pituitary gland organogenesis in the absence of neural crest, and uncovered a critical role for neural crest contributions to the pituitary vasculature.

\section{Results}

$\operatorname{Tg}($ Wnt1-cre)11Rth (abbreviated here as Wnt1-cre) and C57BL/6 J-Tg(PO-Cre)94Imeg (PO-cre) are frequently used to fate map and generate tissue specific loss-of-function alleles in the neural crest $[20,21]$. To determine the contributions of the neural crest to head mesenchyme near the developing pituitary gland we crossed both the Wnt1cre and PO-cre lines with the reporter lines B6.Gt(ROSA)26Sor ${ }^{\text {tm } 4(\text { ACTB-tdTomato,-EGFP)Luo }}\left(\right.$ Rosa $\left.^{m T / m G}\right)$ and Gt (ROSA)26Sor ${ }^{\text {tm1Sho }}$ (Rosa $\left.{ }^{\text {stopLacZ }}\right)$ to determine neural crest contributions to the pituitary adjacent head mesenchyme $[22,23]$. At embryonic day of development 8.5 (e8.5) both Wnt1-cre and P0-cre mediate recombination in the migrating neural crest cells (Fig. 1a and b). The Wnt1-cre also mediates recombination in the midbrain, a domain of cre activity that is not observed in the PO-cre. The midbrain activity of Wnt1-cre is also observed at e12.5, but it is not confined to the midbrain, as $L a c Z$ is expressed in the posterior diencephalon and in the anterior hindbrain (Fig. 1c). At e12.5 the head mesenchyme rostral to Rathke's pouch expresses $L a c Z$, indicating that it is derived from the neural crest (Fig. 1d and e). The head mesenchyme caudal to Rathke's pouch is devoid of X-gal staining, suggesting that this tissue is derived from definitive mesoderm [7, 24, 25]. A sharp boundary between the neural crest derived head mesenchyme and the definitive mesenchyme is observed ventral to Rathke's pouch in midsagittal sections (Fig. 1d). Rathke's pouch is located at the rostral end of the notochord, and chick explants studies demonstrate that the notochord may be involved in Rathke's pouch formation [8, 26, 27]. At more lateral sections the boundary between neural crest and definitive mesoderm is not as sharp, as the definitive mesoderm extends past the lateral edge of Rathke's pouch (Fig. 1e). At e14.5 X-gal stained cells are detected in the forming pituitary anterior lobe of Wnt1-cre; Rosa ${ }^{\text {stopLacZ }}$ embryos, suggesting that the neural crest derived mesenchyme is invading the oral ectoderm-derived Rathke's pouch tissue (Fig. 1f). By e18.5 Wnt1-cre expressing cells have made a significant contribution to the pituitary gland (Fig. 1g). Lineage tracing in P0-cre; Rosa ${ }^{\text {stopLacZ }}$ embryos at e12.5 also demonstrates a sharp boundary between neural crest and definitive mesoderm at mid-sagittal locations (Fig. 1h). Although Wnt1-cre activity in the midbrain and neural crest and PO-cre activity in the neural crest mimic endogenous Wnt1 and PO expression, we also observed ectopic activity in the ventral diencephalon for both cre lines (Fig. 1d and h), and cre activity in Rathke's pouch for the P0-cre (Fig. 1h).

Previous work established that Wnt1-cre mediated deletion of $\beta$-catenin causes neural crest cells to undergo apoptosis during migration, which provides a method to generate neural crest deficient embryos [19]. Because pituitary development was not analyzed in these embryos, we crossed Wnt1-cre with B6.129-Ctnnb1 $1^{\text {tm2Kem } / K n w J ~}$ (referred to here as $\beta$-cat $f^{f x / f x}$ ) and then generated Wnt1cre; $\beta$-cat $f^{f x / f x}$ embryos to determine if the neural crest 

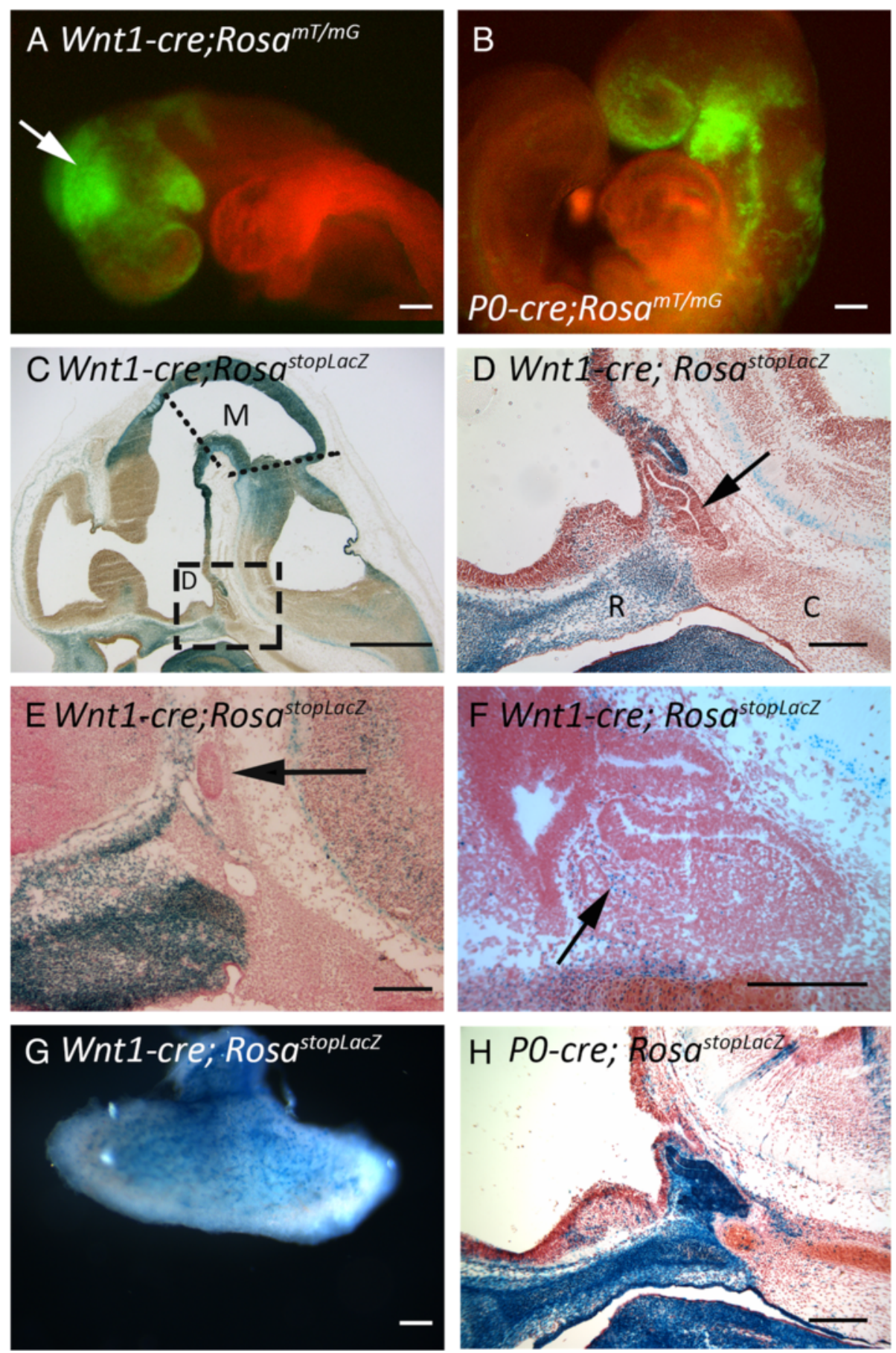

Fig. 1 a-b Rosa ${ }^{m T / m G}$ reporter mice enable fluorescent detection of cre recombinase activity, where green fluorescence indicates areas of cre recombination and red fluorescence indicates areas with no recombination. a Wnt 1-cre; Rosa ${ }^{\mathrm{mT} / \mathrm{mG}}$ e8.5 embryo. Arrow indicates recombinase activity in the midbrain. b PO-cre; Rosa ${ }^{\mathrm{mT} / \mathrm{mG}}$ e8.5 embryo. c-h X-gal staining (blue) reveals cre recombinase activity in Rosa ${ }^{\text {stoplacz }}$ reporter mice. $\mathbf{c}-\mathbf{f}$ and $\mathbf{h}$ sagittal sections counterstained with neutral red. c Mid-sagittal section of an e12.5 Wnt1-cre; Rosa ${ }^{\text {stoplacZ }}$ embryo. Dotted lines indicate the midbrain (M) boundaries with the diencephalon and hindbrain. The boxed area is magnified in $\mathbf{d}$. $\mathbf{d}$ Boxed area indicated in $\mathbf{c}$. Arrow indicates Rathke's pouch; R indicates rostral head mesenchyme; C indicates caudal head mesenchyme e e12.5 Wnt1-cre; Rosa ${ }^{\text {stoplacz }}$ section at the lateral extreme of Rathke's pouch (arrow). $\mathbf{f}$ e14.5 Wnt1-cre; Rosa ${ }^{\text {stoplacz. }}$. Arrow indicates X-gal stained cells within the pituitary anterior lobe. $\mathbf{g}$ Ventral view of a dissected e18.5 Wnt1-cre; Rosa ${ }^{\text {stoplacz }}$ pituitary. $\mathbf{h}$ Mid-sagittal section of an e12.5 P0-cre; RosatoplacZ embryo. Scale bars in $\mathbf{a}, \mathbf{b}$, and $\mathbf{d}-\mathbf{h}$ equal $100 \mu \mathrm{m}$. Scale bar in c equals $1 \mathrm{~mm}$ 
derived head mesenchyme is important for pituitary organogenesis. Indeed, Wnt1-cre; $\beta$-cat ${ }^{f x / f x}$ embryos do have abnormalities in pituitary development (Fig. 2a-i). At early stages of Rathke's pouch formation (e10.5) a larger domain of oral ectoderm is recruited into Rathke's pouch, as marked by immunostaining for the critical LIM homeodomain transcription factor, LHX3 (Fig. 2b and c). At e12.5 the enlarged, mutant Rathke's pouch includes more oral ectoderm tissue than typical, extending more rostrally than normal (Fig. 1e). The enlarged domain of presumptive pituitary tissue becomes highly dysmorphic (Fig. 2f). The abnormal pituitary extends through the cartilage plate that underlies the pituitary gland at e18.5 and can form an anterior lobe like structure that projects into the oral cavity at more rostral locations (Fig. $2 \mathrm{~h}$ and i).

The number and distribution of hormone expressing cell types in the pituitary anterior lobe in both wild type and Wnt1cre; $\beta$-cat $t^{f x / f x}$ embryos was examined by immunostaining for pituitary hormones at e18.5 (Fig. 3a-h). No obvious difference in the quantity or distribution of anterior lobe cell types was detected between the wild type and mutant embryos, despite the highly dysmorphic, mutant pituitary gland.

The dysmorphic pituitary of Wnt1cre; $\beta$-cat ${ }^{f x / f x}$ embryos resembles those of other genetically modified mouse embryos that have an expansion of the pituitary organizer in the ventral diencephalon [6]. The pituitary organizer is characterized in part by the expression of Fgf10 and Bmp4, which are necessary for the induction and proliferation of Rathke's pouch [28, 29]. We examined Bmp4 and Fgf10 expression in wild type and Wnt1cre; $\beta$-cat ${ }^{f x / f x}$ embryos by in situ hybridization and found that the mutant embryos have expanded expression domains of both morphogenetic proteins (Fig. 4a d). The expression domain of the transcription factor SIX6 typically exists in the ventral diencephalon rostral to the pituitary organizer. Six6 expression is shifted rostrally from Rathke's pouch in the mutant embryos (Fig. $4 \mathrm{e}-\mathrm{f}$ ). These results demonstrate that the patterning within the ventral diencephalon is disrupted in Wnt1cre; $\beta$-cat ${ }^{f x / f x}$ embryos. Excess BMP and FGF signaling from the pituitary organizer likely contributes to the recruitment of additional oral ectoderm into Rathke's pouch [9, 30-32].

Wnt1-cre is expected to drive recombination in multiple tissues where loss of $\beta$-catenin could affect pituitary organogenesis, including the neural crest and ventral diencephalon. We examined $\beta$-CATENIN expression by immunohistochemistry to determine the efficiency of cre recombination in these tissues (Fig. 5a-f). At e12.5 the Wnt1-cre; $\beta$-cat ${ }^{f x / f x}$ embryos do not express $\beta$-CATENIN
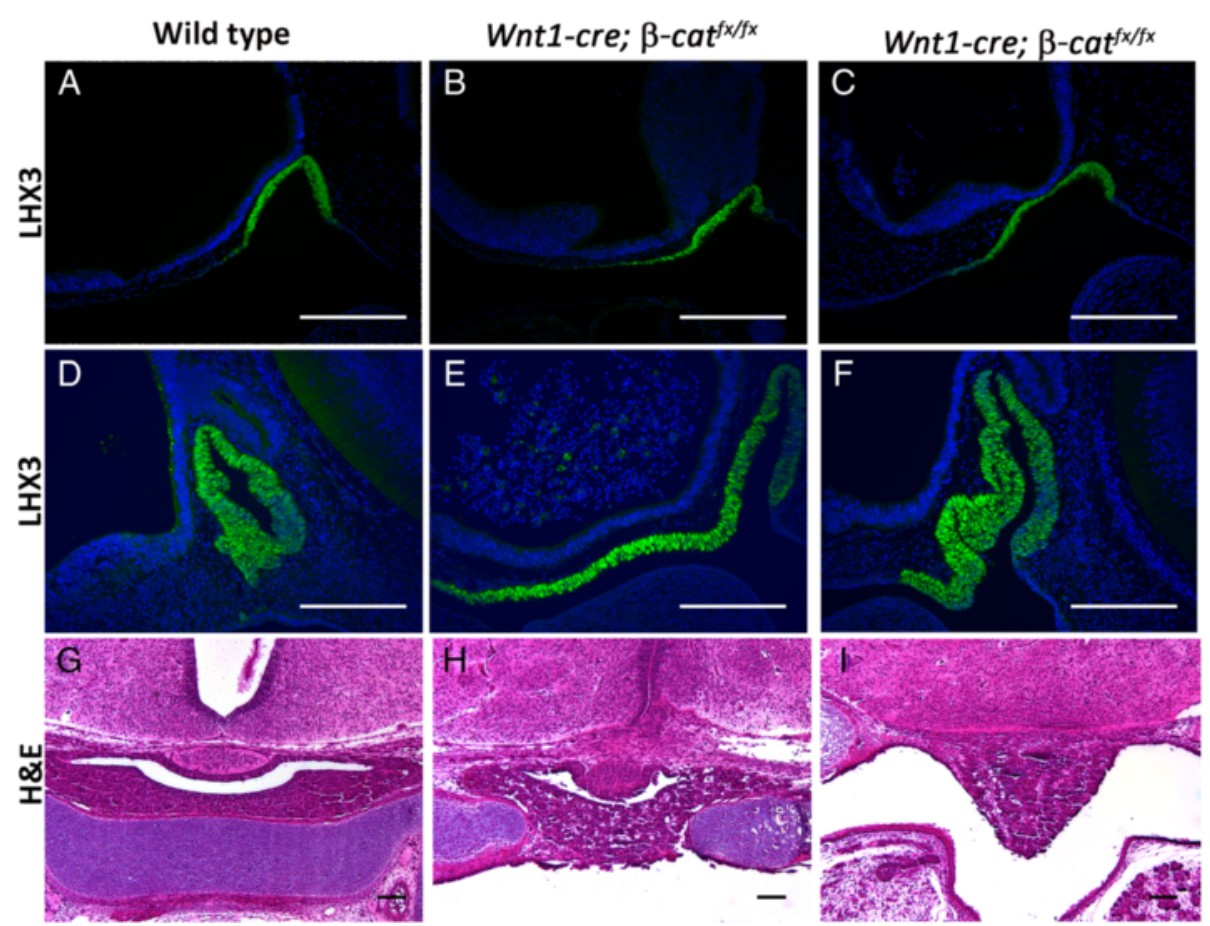

Fig. 2 a - f $L H X 3$ immunostaining (green) on sagittal sections, counterstained with DAPI (blue). a Wild type e10.5 b \& c Two separate Wnt1-cre; $\beta$-cat ${ }^{f x / f x}$ e10.5 embryos d Wild type e12.5 e \& f Two separate Wnt1-cre; $\beta$-cat fxftx e12.5 embryos $\mathbf{g}-\mathbf{i}$ Hemotoxylin and eosin staining on e18.5 coronal sections $\mathbf{g}$ Wild type $\mathbf{h} \& \mathbf{i}$ Two sections from the same Wnt7-cre; $\beta$-cat ${ }^{\text {fx/fx }}$ embryo, with I representing a more rostral location. All scale bars equal $100 \mu \mathrm{m}$ 

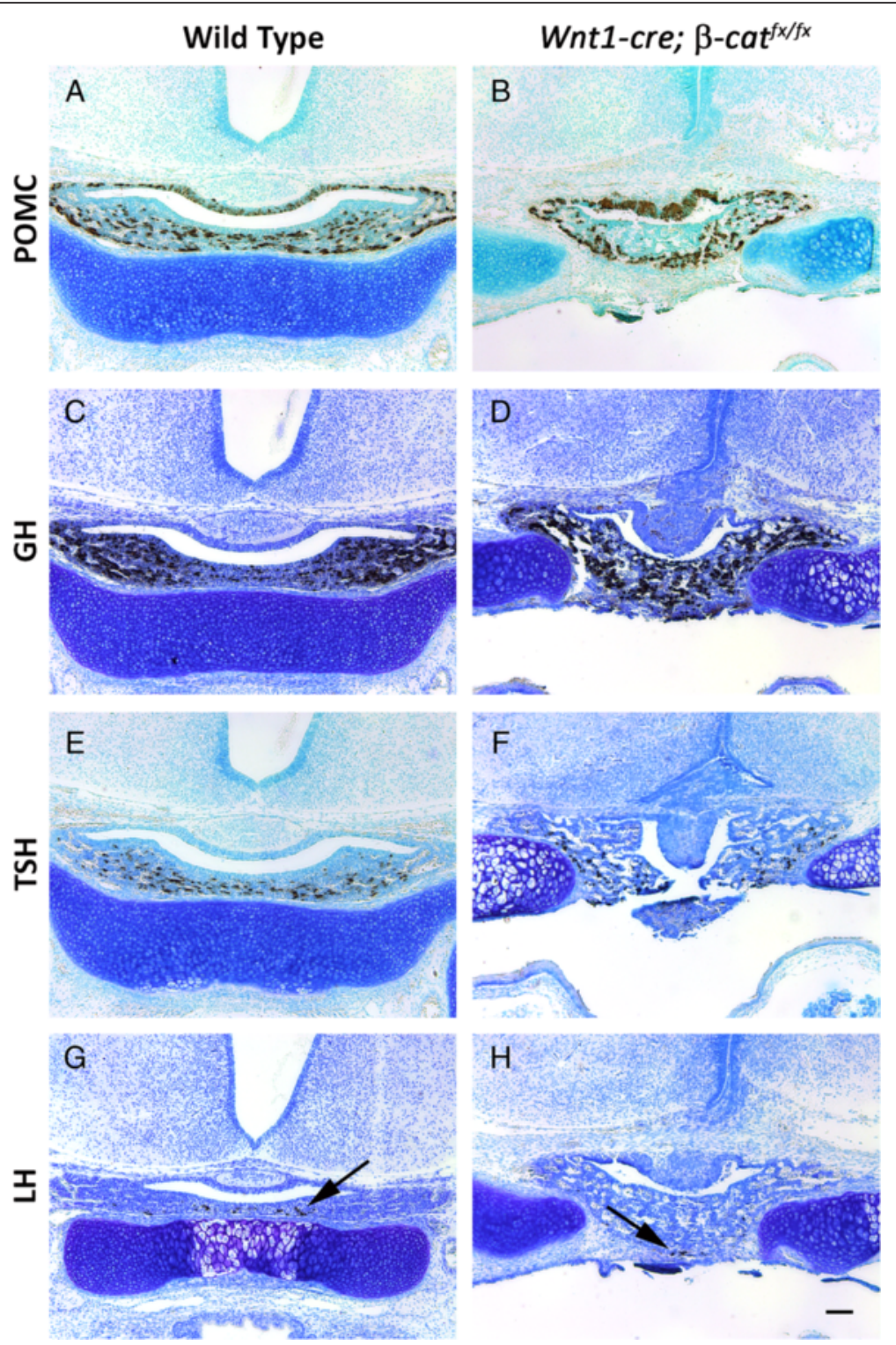

Fig. 3 Immunostaining for pituitary anterior and intermediate lobe hormones (brown) at e17.5, counterstained with methyl green (blue). a \& $\mathbf{b}$ Proopiomelanocortin (POMC) c \& d Growth hormone (GH) e \& $\mathbf{f}$ Thyroid stimulating hormone (TSH) $\mathbf{g} \& \mathbf{h}$ Luteinizing hormone (LH), arrows indicate select positive cells. a, c, e, \& $\mathbf{g}$ Wild type $\mathbf{b}, \mathbf{d}, \mathbf{f}, \& \mathbf{h}$ Wnt1-cre; $\beta$-cat ${ }^{f x}$. . Scale bar in H equals $100 \mu m$ for all images

in the residual neural crest derived mesenchyme rostral to Rathke's pouch, indicating that Wnt1-cre efficiently recombines the conditional $\beta$-catenin allele in this tissue (Fig. 5d and e). Wnt1-cre is not uniformly active within the ventral diencephalon, and only small clumps of cells exhibit loss of $\beta$-CATENIN (Fig. 5d and $\mathrm{f}$ ). This level of $\beta$-catenin ablation is unlikely to alter ventral diencephalon patterning. However, we may be underestimating the degree of $\beta$-catenin ablation as the protein persists in the adherens junctions for many hours following recombination at the $\beta$-catenin locus [33]. In addition, the presence of $\beta$-CATENIN protein in the adherens junctions does not maintain canonical Wnt signaling after cre mediated recombination [33]. Therefore, we cannot rule out the possibility that $\beta$-catenin ablation in the infundibular domain may result in an expansion of the pituitary organizer.

We sought to recapitulate the Wht1-cre; $\beta$-cat $f^{f x f x}$ phenotype using the PO-cre, which is also active in the neural crest and has some ectopic activity in the ventral diencephalon, to confirm that loss of $\beta$-catenin in these domains causes the pituitary phenotype. P0-cre; $\beta$-cat $t^{f x / f x}$ embryos have severe craniofacial malformations compared to wild type littermates consistent with a neural crest deficiency (Additional file 1: Figure S1), and similar in phenotype to Wnt1-cre; $\beta$-cat ${ }^{f x / f x}$ embryos [19]. 

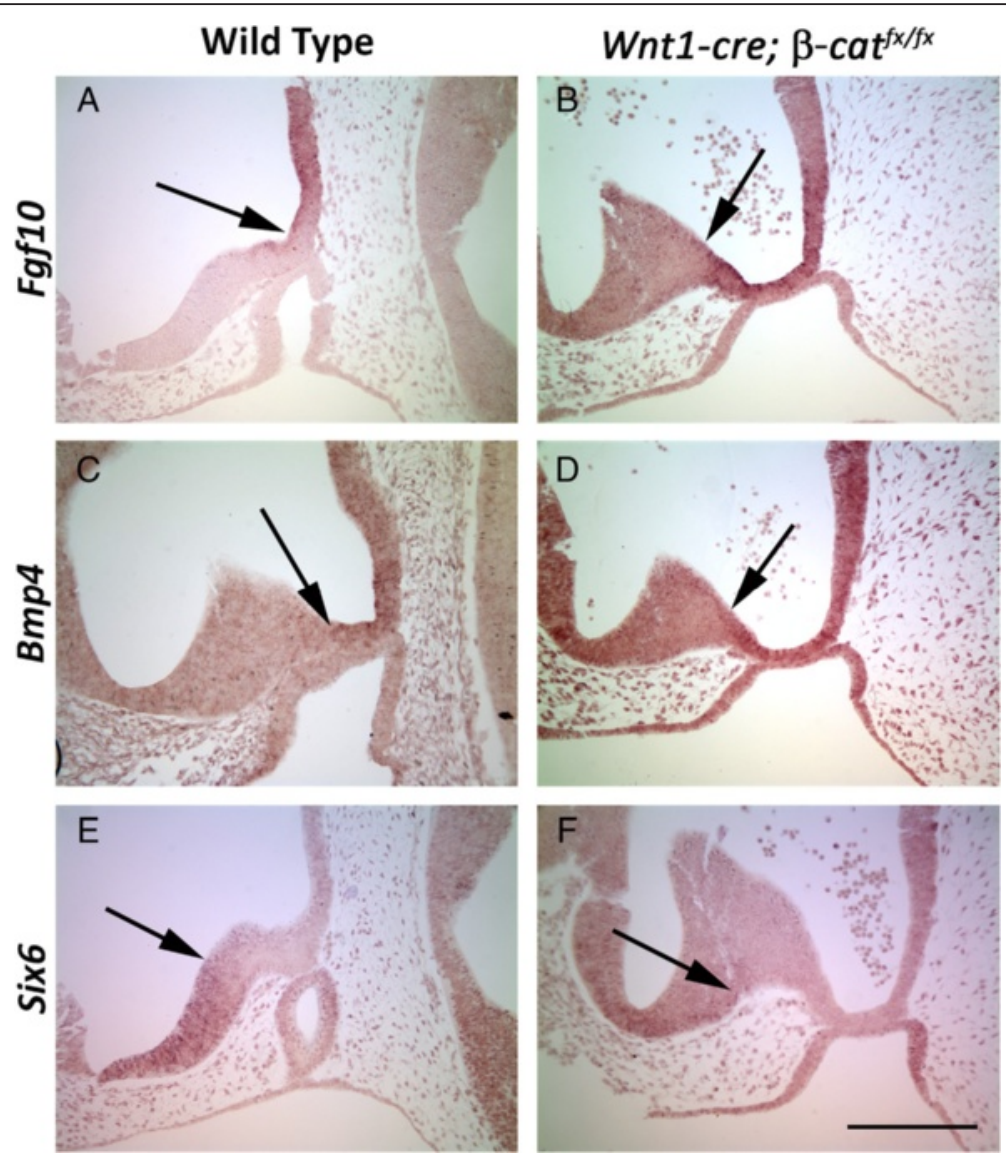

Fig. 4 RNA in situ hybridization on e10.5 sagittal sections (brown). Arrows represent the boundary of expression between the domain of Bmp4 and Fgf10 expression and adjacent Six6 expressing domain in the ventral diencephalon. a \& b Fgf10 c \& d Bmp4 e \& f Six6 a, c, \& e Wild type b, d, \& f Wnt 1 -cre; $\beta$-cat ${ }^{\text {fx/fx }}$. Scale bar in F equals $100 \mu \mathrm{m}$ for all images
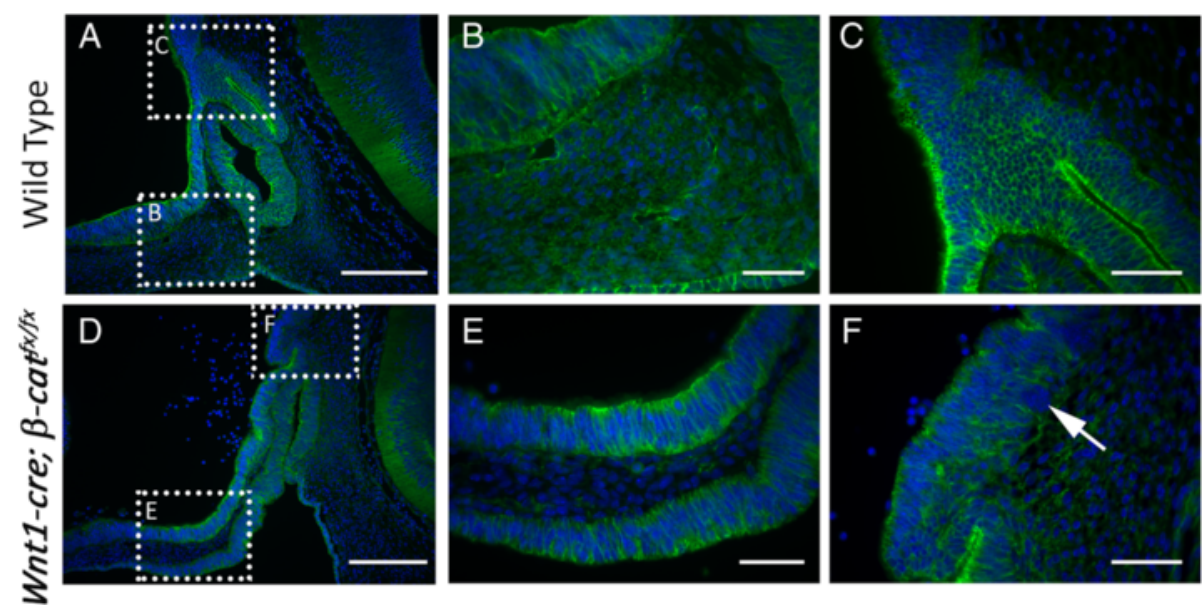

Fig. 5 Immunostaining for $\beta$-CATENIN (green) on e14.5 sagittal sections, counterstained with DAPI (blue) a-c Wild type, boxed regions in a are magnified in $\mathbf{b}$ and $\mathbf{c}$. $\mathbf{b}$ Region highlighting neural crest derived mesenchyme $\mathbf{c}$ Region highlighting ventral diencephalon $\mathbf{d}-\mathbf{f}$ Wnt 1 -cre; $\beta$-cat ${ }^{f \times}$ $f x$, boxed regions in $\mathbf{d}$ are magnified in $\mathbf{e}$ and $\mathbf{f}$. e Region highlighting neural crest derived mesenchyme where $\beta$-CATENIN is lost $\mathbf{f}$ Region highlighting ventral diencephalon where b-catenin is maintained. Arrow indicates a small region with no $\beta$-CATENIN expression. Scale bars in a and $\mathbf{d}$ equal $100 \mu \mathrm{m}$, scale bars in $\mathbf{b}, \mathbf{d}$, e, and $\mathbf{f}$ equal $20 \mu \mathrm{m}$ 
However, unlike Wnt1-cre; $\beta$-cat ${ }^{f x / f x}$ embryos, the pituitary morphology of $P 0$-cre; $\beta$-cat $t^{f x / f x}$ mutant embryos is very similar to wild type despite the absence of neural crest derived cranial mesenchyme rostral to Rathke's pouch, as evidenced by the absence of the cartilage plate rostral to the pituitary gland (Fig. 6a and b). Using immunostaining we determined that the PO-cre efficiently recombines the conditional $\beta$-catenin allele in the neural crest, but not in the ventral diencephalon at e12.5 (Fig. 6g-i). Within Rathke's pouch, variable, small patches of $\beta$-CATENIN deficient cells are observed, but $\beta$-CATENIN is not completely eliminated (Fig. 6j). Thus, both Wnt1-cre and PO-cre are similarly effective in deleting $\beta$-catenin in the neural crest, but the P0-cre does not delete $\beta$-catenin in the ventral diencephalon. Therefore, the Wnt1-cre; $\beta$-cat ${ }^{f x / f x}$ dysmorphic pituitary is not caused by the loss of neural crest cells.

The PO-cre can drive recombination in Rathke's pouch, and $\beta$-CATENIN can influence the activity of the transcription factors PROP1, PIT1 (POU1F1), PITX2, and SF1 (NR5A1) in the pouch and its derivatives [34-37]. Therefore, we sought to determine if the ectopic, mosaic loss of $\beta$-CATENIN in the P0-cre; $\beta$-cat ${ }^{f x / f x}$ pouch could alter anterior lobe cell specification. No significant changes in hormone expressing cell types were observed in the mutant embryos (Fig. 7a $-\mathrm{h}$ ), indicating that the mosaic loss of $\beta$-CATENIN in Rathke's pouch does not disrupt pituitary cell specification.

Wnt signaling in the ventral diencephalon is known to regulate the expression domain of the pituitary organizer $[30,31]$. While the mosaic loss of $\beta$-catenin in the ventral diencephalon observed with Wnt1-cre is unlikely to alter pituitary organizer activity, we sought to inactivate $\beta$-catenin in the ventral diencephalon to determine if canonical Wnt signaling mediates pituitary organizer expression. We crossed Shh ${ }^{\text {tm1(EGFP/cre)Cjt }}$ (Shh-cre) with Rosa $^{\text {stopLacZ }}$ and stained embryo sections with X-gal. We detected staining in the ventral diencephalon and the oral ectoderm at e10.5 in a pattern that recapitulates the endogenous expression of Shh (Additional file 2: Figure S2a) [38]. We next crossed the Shh-cre with $\beta$-cat fx/fx to determine if the loss of $\beta$-catenin in the ventral diencephalon would lead to an expanded pituitary organizer and an expansion of Rathke's pouch. At e12.5 the pituitaries of Shh-cre; $\beta$-cat $t^{f x / f x}$ embryos were indistinguishable from wild type littermates (Additional file 2: Figure S2b-c). The lack of $\beta$-catenin in the Shh expressing domain of the fore and hind limbs leads to disruptions in digit formation, as expected (Additional file 2: Figure S2d-f). Previous studies have demonstrated that $\beta$-catenin is necessary for maintaining limb mesenchyme and Fgf10 expression in the apical ectodermal ridge [39]. We used immunostaining to determine whether the Shh-cre effectively deleted $\beta$-CATENIN in the ventral diencephalon. Although there were patches of cells that were negative for $\beta$-CATENIN immunostaining, the majority of cells in the ventral diencephalon retained $\beta$ CATENIN expression (Additional file 2: Figure $\mathrm{S} 2 \mathrm{~g}-\mathrm{i}$ ). We concluded that unlike in the limb bud, the Shh-cre is unable to efficiently recombine the $\beta$-cat $t^{f x / f x}$ allele in the ventral diencephalon, leaving canonical Wnt signaling largely intact. This result also confirms that the mosaic loss of $\beta$-catenin in the ventral diencephalon is insufficient for producing the dysmorphic pituitaries of Wnt1-cre; $\beta$-cat ${ }^{f x / f x}$ embryos.

There are many precedents for variability in cre-mediated deletion, including parent-of-origin effects, episome formation, number of conditional alleles, and genetic background differences, any of which could affect the activity of the transgenic cre lines used in this study [40-43]. However, the three cre lines used here demonstrate that $\beta$-catenin deletion in the neural crest and mosaic $\beta$-catenin deletion in the ventral diencephalon do not generate a dysmorphic pituitary gland. The major difference in activity between the cre lines is the expression of Wnt1-cre in the midbrain.

We tested the possibility that loss of $\beta$-catenin in the midbrain results in patterning disruptions of the ventral diencephalon by examining additional markers of the posterior ventral diencephalon. Our fate mapping studies suggest that the Wnt1-cre is also active in the posterior diencephalon (Fig. 1c). Immunoflourescence for $\beta$ CATENIN on e11.5 wild type and Wnt1-cre; $\beta$-catenin ${ }^{f x /}$ $f x$ embryos demonstrates that $\beta$-CATENIN expression is lost in many cells near the boundary of the midbrain and posterior diencephalon (Fig. 8a-d). Otx2 is expressed in the forebrain and midbrain and is necessary for forming the isthmic organizer at the midbrain/hindbrain boundary [44-46]. During Rathke's pouch induction, OTX2 is expressed in the infundibulum and more posterior regions of the ventral diencephalon, but is excluded from the neural ectoderm rostral to the infundibulum [47]. At e11.5 OTX2 is strongly expressed in the posterior diencephalon, but has a lower level of expression in the infundibulum (Fig. 1e and f). In Wnt1cre; $\beta$-cat $t^{f x / f x}$ embryos OTX2 is strongly expressed in the infundibulum and a domain of weaker OTX2 expression is observed rostral to the infundibulum (Fig. $8 \mathrm{~g}$ and h). Lef1 is expressed in the premamillary region of the developing hypothalamus [48]. This domain of LEF1 expression is not contiguous with the infundibulum (Fig. $8 \mathrm{i}$ and j). In Wnt1-cre; $\beta$-cat ${ }^{f x / f x}$ embryos the boundary of LEF1 expression is displaced rostrally and corresponds to the caudal edge of the infundibulum (Fig. 8k and l). These results demonstrate that the patterning of the entire posterior ventral diencephalon, including the pituitary organizer, is shifted rostrally when $\beta$-catenin is deleted by the Wnt1-cre. 

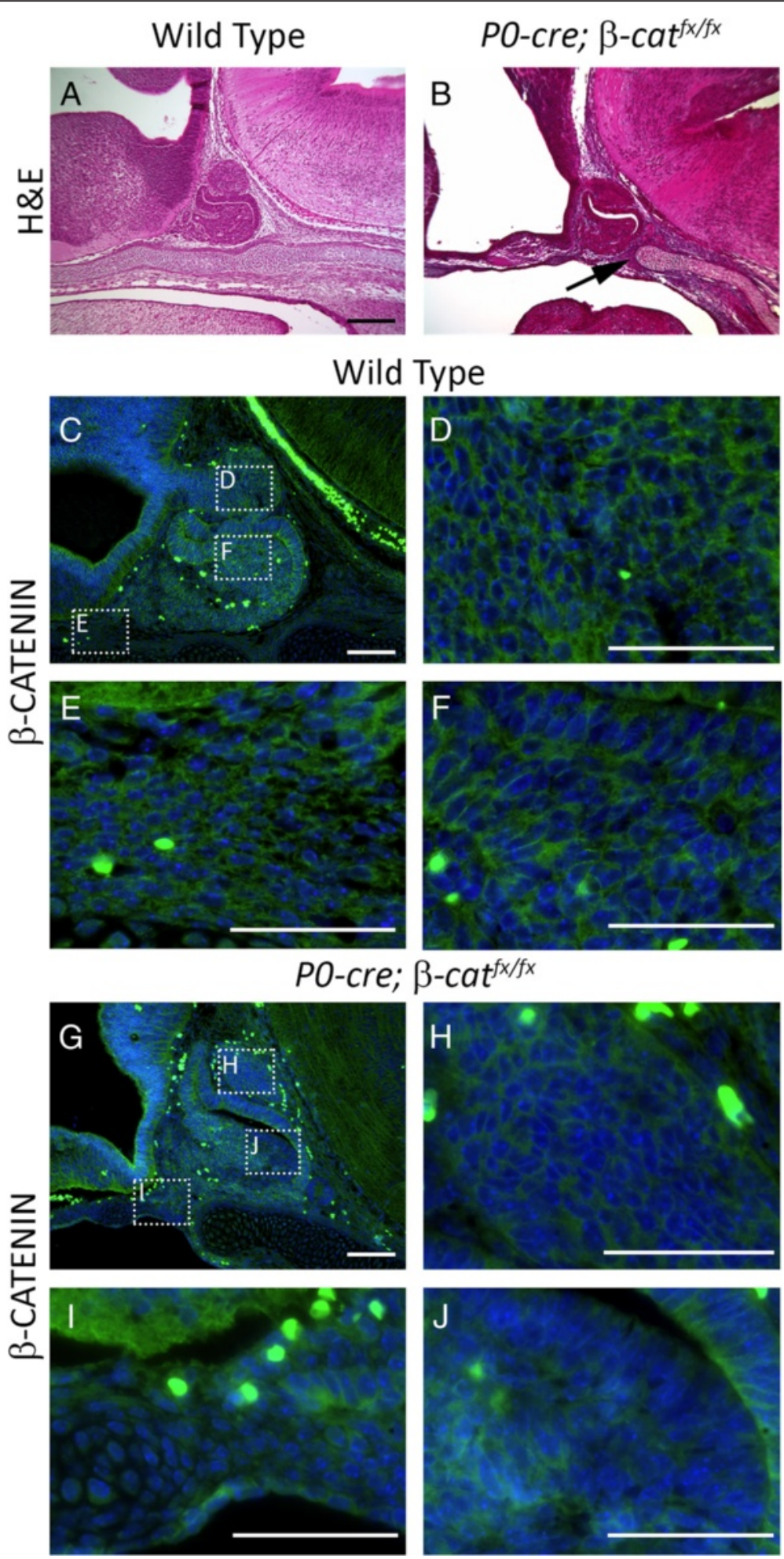

Fig. $\mathbf{6}$ a \& $\mathbf{b}$ Hemotoxylin and eosin staining on e14.5 sagittal sections a Wild type $\mathbf{b} P 0$-cre; $\beta$-cat ${ }^{f x / f x}$, arrow indicates the end of cartilage plate that will form the sphenoid bone. $\mathbf{c}-\mathbf{j}$ Immunostaining for $\beta$-CATENIN (green) on e14.5 sagittal sections, counterstained with DAPI (blue) $\mathbf{c}-\mathbf{f}$ Wild type, boxed regions in $\mathbf{c}$ are magnified in $\mathbf{d}$, $\mathbf{e}$, and $\mathbf{f}$. $\mathbf{d}$ Region highlighting the ventral diencephalon $\mathbf{e}$ Region highlighting the neural crest derived mesenchyme. $\mathbf{f}$ Region highlighting the pituitary anterior lobe. $\mathbf{g}-\mathbf{j} P 0-c r e ; \beta$-cat ${ }^{f \times / f x}$, boxed regions in $\mathbf{g}$ are magnified in $\mathbf{h}, \mathbf{i}$, and $\mathbf{j}$. $\mathbf{h}$ Region highlighting the ventral diencephalon. i Region highlighting the neural crest derived mesenchyme. $\mathbf{j}$ Region highlighting the pituitary anterior lobe. Scale bars equal $100 \mu \mathrm{m}$ for $\mathbf{a}-\mathbf{c}$ and $\mathbf{g}$. Scale bars equal $50 \mu \mathrm{m}$ for $\mathbf{d}-\mathbf{f}$ and $\mathbf{h}-\mathbf{j}$ 

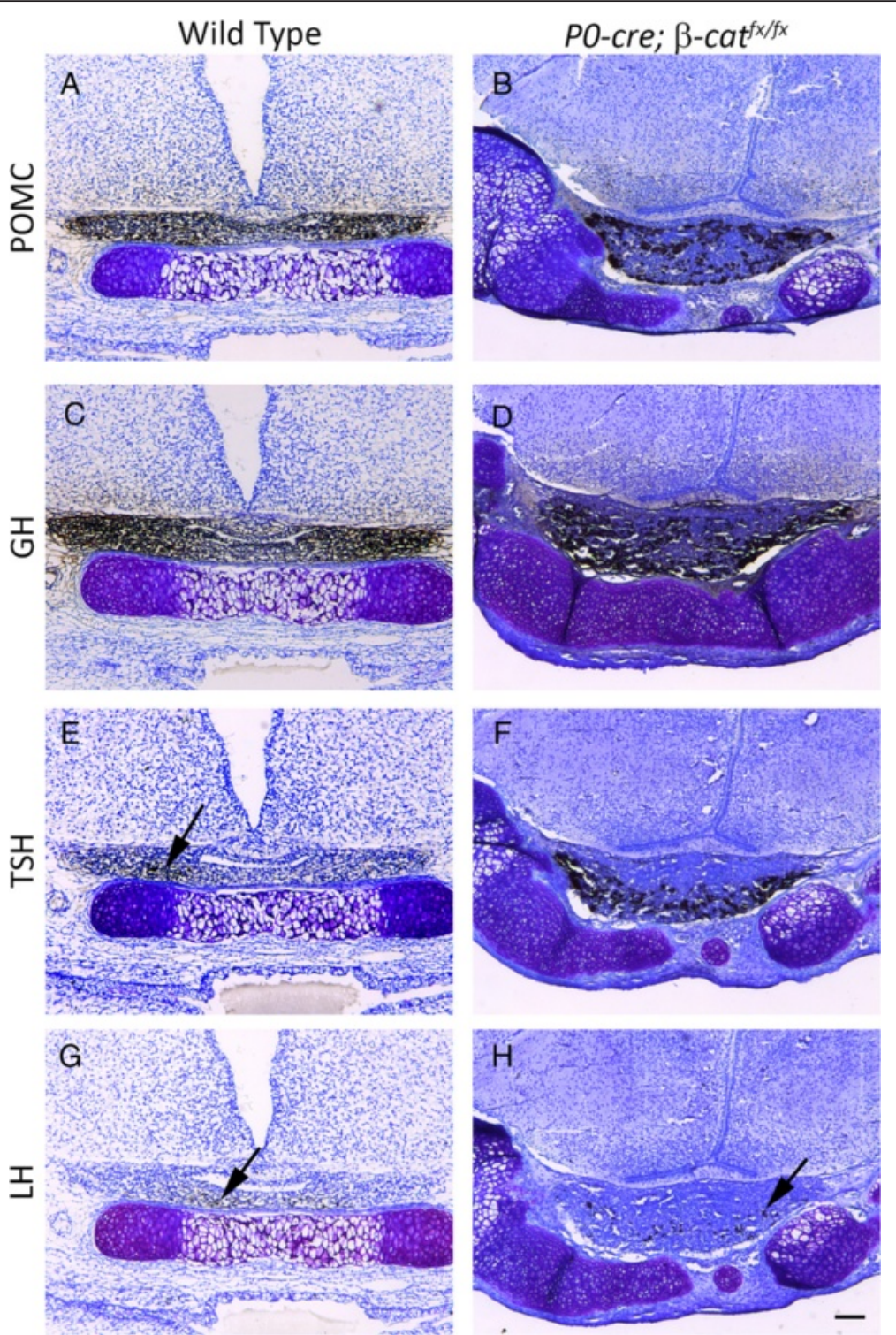

Fig. $7 \mathbf{a}-\mathbf{h}$ Immunostaining for pituitary anterior and intermediate lobe hormones (brown) at e17.5, counterstained with methyl green (blue). a $\& \mathbf{b} P O M C \mathbf{c} \& \mathbf{d} G H \mathbf{e} \& \mathbf{f} T S H \mathbf{g} \& \mathbf{h} L H$. $\mathbf{a}, \mathbf{c}, \mathbf{e}, \& \mathbf{g}$ Wild type $\mathbf{b}, \mathbf{d}, \mathbf{f}, \& \mathbf{h} P O$-cre; $\beta$-cat ${ }^{f \times f f}$. Arrows in $\mathbf{e}, \mathbf{g}$, and $\mathbf{h}$ indicate positively stained cells. Scale bars equal $100 \mu \mathrm{m}$ for all images

The pattern of LacZ expression in the e18.5 Wnt1-cre; Rosa $a^{\text {stopLac } Z}$ pituitary suggests that the neural crest contributes to the pituitary vasculature (Fig. 1f). Therefore, we examined the pituitary vasculature in both models of neural crest deficient embryos using immunostaining for CD31 (PECAM), an endothelial cell marker (Fig. 9a-h). The blood vessels in the pituitary glands of both the Wnt1-cre; $\beta$-cat $t^{f x / f x}$ and P0-cre; $\beta$-cat $t^{f x / f x}$ embryos are abnormally dilated at e18.5 (Fig. 9a-f). Endothelial cells appear to be migrating into the forming pituitary anterior lobe at e14.5 (Fig. 9g). Neither this pattern nor the size of the forming endothelium is disrupted in PO-cre; $\beta$-cat $t^{f x / f x}$ embryos, suggesting that the early migration of endothelial cells into the pituitary anterior lobe is unaffected by the loss of the neural crest (Fig. 9h). Pericytes are cells that wrap around the endothelium and regulate blood vessel diameter, and the pericytes of the head are neural crest-derived $[17,18]$. Pericytes express PDGFR $\beta$ at e18.5 in wild type mouse embryos (Fig. 9i). This pericyte marker is absent in PO-cre; $\beta$-cat ${ }^{f x / f x}$ embryos, confirming that the loss of neural crest cells results in a loss of pituitary gland pericytes (Fig. 9j). $P D G F \beta^{-/-}$or $P D G F R \beta^{-/-}$mice develop dilated and leaky vasculature throughout the body that is similar to the vascular defects we observed in the pituitary glands of the PO-cre; $\beta$-cat ${ }^{f x f f}$ embryos [49-51]. 


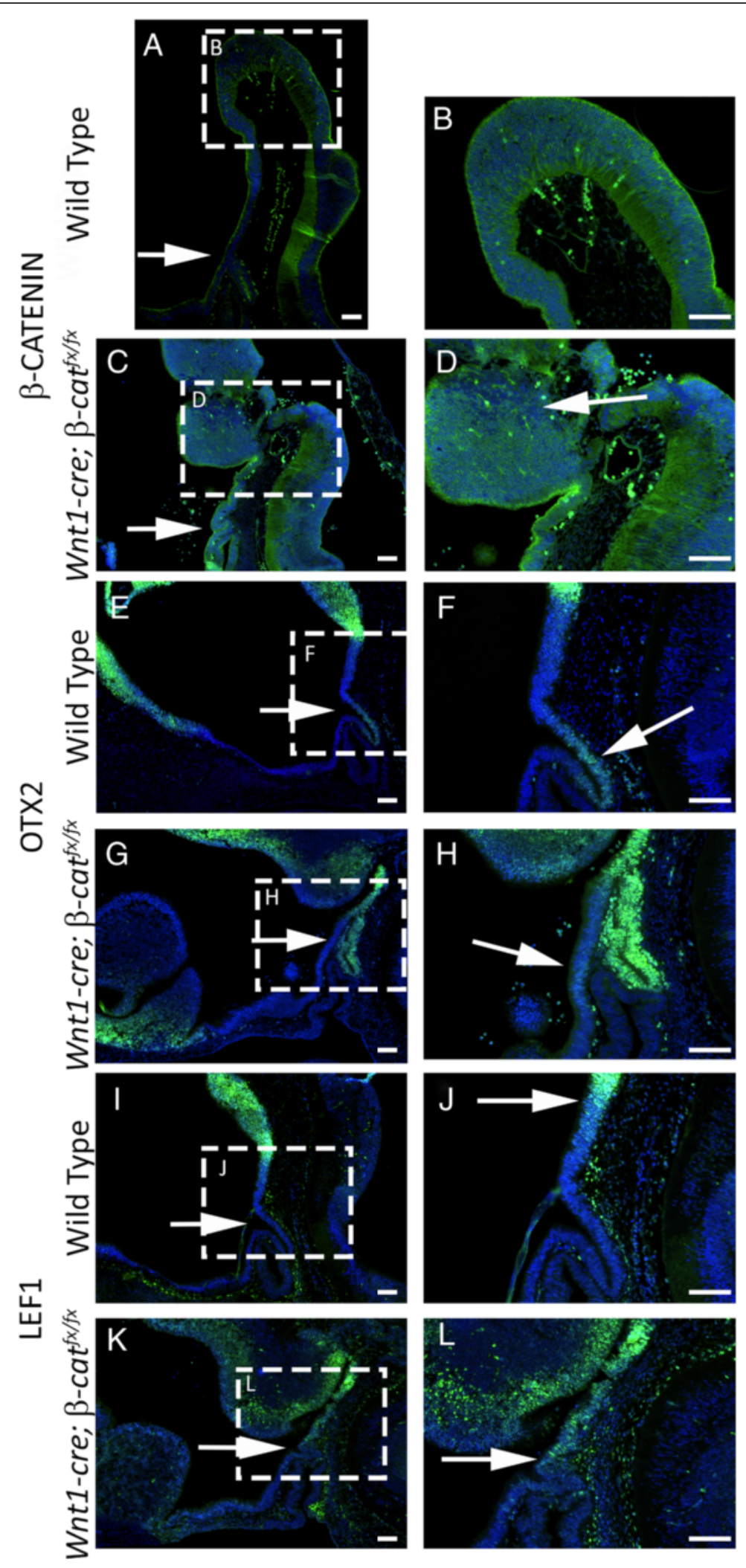

Fig. 8 (See legend on next page.) 


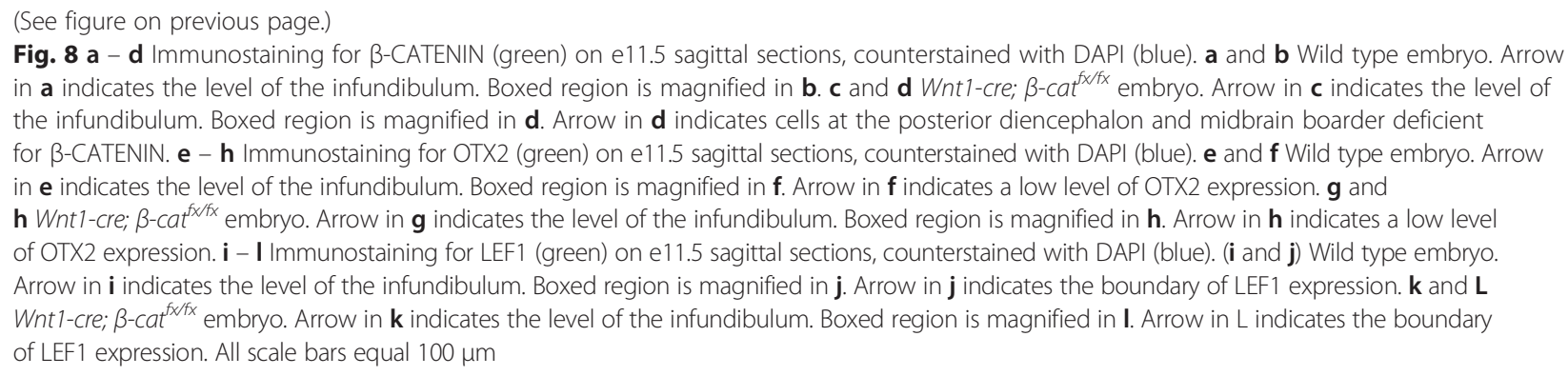

\section{Discussion}

The developing pituitary gland is surrounded by head mesenchyme, which has a dual origin from definitive mesoderm and neural crest $[4,24]$. Using two different neural crest expressing transgenic cre lines, we have shown that at axial levels the head mesenchyme on the rostral side of Rathke's pouch is of neural crest origin. This result is in agreement with previous fate mapping experiments of the neural crest derived head mesenchyme [25]. The mesenchyme on the caudal side is derived from definitive mesoderm; the rostral end of the notochord and the prechordal mesoderm is located on the caudal side of Rathke's pouch [24, 26, 27]. At more lateral levels the boundary between neural crest and definitive mesoderm is still present, but the definitive mesoderm can migrate to the rostral side of Rathke's pouch. The separation between head mesenchyme of neural crest and definitive mesoderm origins on either side of the pituitary gland presents intriguing possibilities for differential effects of these mesenchymal populations on pituitary gland organogenesis. For instance, stimulation of Notch signaling in the ventral diencephalon reduces $\mathrm{Fgf10}$ expression in the pituitary organizer, which reduces $L h x 3$ expression in Rathke's pouch and increases apoptosis [52]. Lhx3 expression is reduced preferentially on the caudal side of Rathke's pouch and apoptosis is preferentially increased [52]. The differential effects on Rathke's pouch may be caused by signals from the definitive mesoderm, which are not expressed in the neural crest derived mesoderm.

Mesenchyme is known to be important for pituitary induction $[8,12]$, but the specific factors involved and source of mesenchyme were unexplored. To address the role of neural crest derived mesenchyme on pituitary organogenesis we examined mouse embryos deficient in neural crest. Intriguingly, ablation of neural crest using two different promoters to drive cre-mediated excision of $\beta$-catenin produced two different pituitary phenotypes. Wnt1-cre mediated deletion of $\beta$-catenin in the neural crest produced Rathke's pouch and pituitary anterior lobe dysmorphology, without an effect on cell specification, while PO-cre mediated deletion had no effect at all, despite equally effective neural crest cell ablation.
The dysmorphic pituitary caused by Wnt1-cre is likely attributable to expansion of the pituitary organizer, including excess Bmp4 and Fgf10 expression, leading to additional oral ectoderm being induced to form Rathke's pouch. This phenotype is similar to other models of pituitary organizer expansion that result in an enlarged Rathke's pouch [9, 30-32].

We considered three possibilities for how Wnt1-cre mediated inactivation of $\beta$-catenin could result in a dysmorphic pituitary, and tested these possibilities by using the Shh-cre and PO-cre. The data from each experiment is summarized in Table 1. The first possibility we considered is that the neural crest pattern the ventral diencephalon, including establishing the rostral boundary of the pituitary organizer, and that neural crest deficient embryos result in a pituitary organizer boundary shift. The neural crest regulate patterning of the forebrain and midbrain [53-55], and could potentially affect patterning in the ventral diencephalon. However, PO-cre, which effectively ablates $\beta$-catenin in the neural crest, does not induce expansion of Rathke's pouch. Therefore, the loss of neural crest cells is unlikely to cause the expansion of the pituitary organizer.

The second possibility is that modest, ectopic deletion of $\beta$-CATENIN in the ventral diencephalon causes expansion of the pituitary organizer. TCF7L2 (TCF4) is a transcription factor that is activated by $\beta$-CATENIN, and $T c f 7 l 2^{-/-}$and $W n t 5 a^{-/-}$embryos both have an expansion of the pituitary organizer that leads to a dysmorphic pituitary $[30,31,56,57]$. These precedents support the idea that the mosaic deletion of $\beta$-catenin in a few patches within the ventral diencephalon could be recapitulating the Wnt5a and Tcf7l2 phenotypes. However, Wnt1-cre and Shh-cre mediate similar mosaic, ectopic $\beta$-CATENIN deletion in the ventral diencephalon, but only Wnt1-cre causes a phenotype. In addition, $\beta$-catenin is only ablated in a few cells of this tissue by either cre strain. Taken together, these facts argue against the possibility that the pituitary phenotype is caused by deletion of $\beta$-CATENIN in the ventral diencephalon.

The third possibility is that Wnt1-cre mediated deletion of $\beta$-catenin in the midbrain results in a rostral shift of the pituitary organizer. The major difference in 

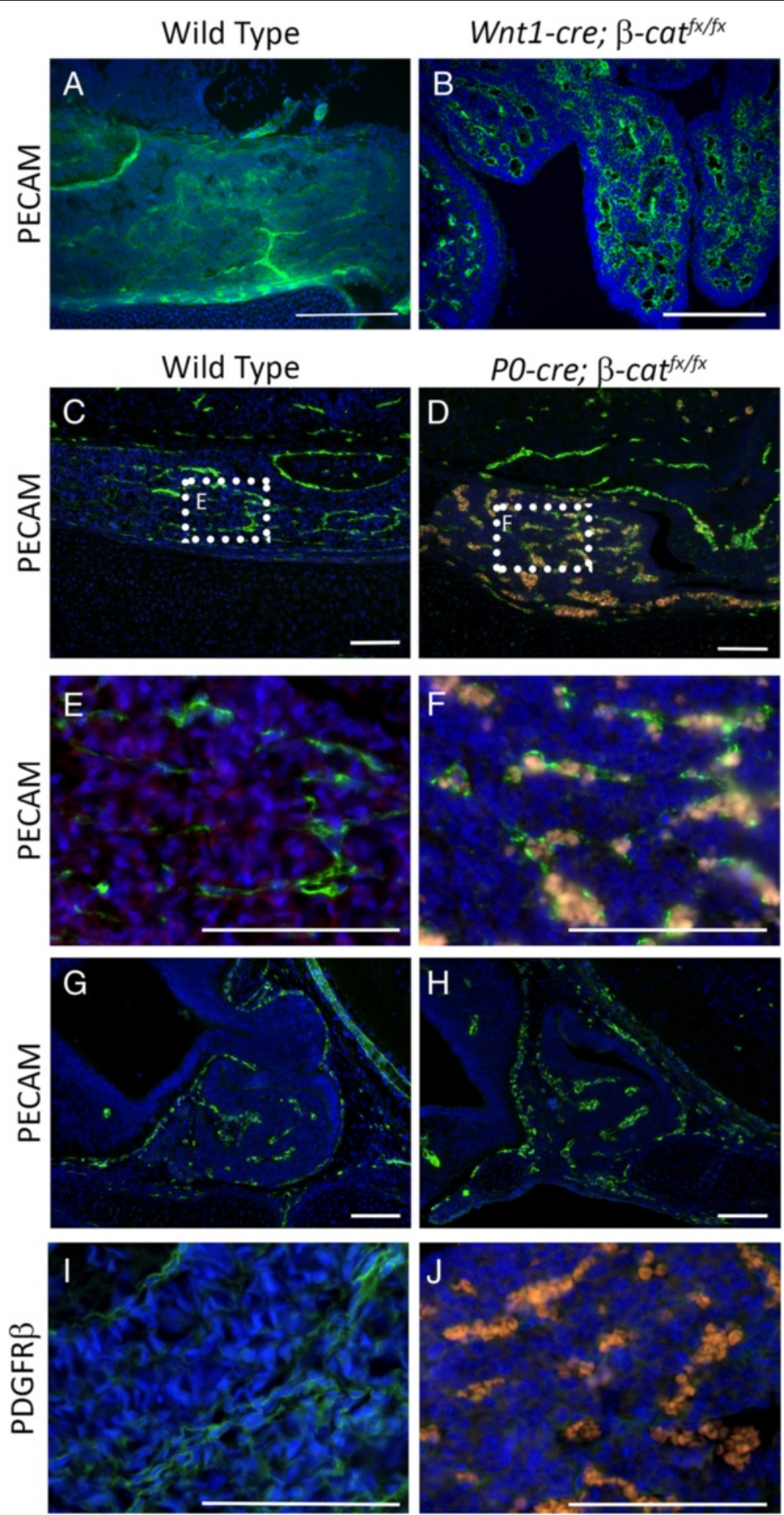

Fig. 9 a - h Immunostaining for PECAM (green), counterstained with DAPI (blue). a Wild type e17.5 cryosection, coronal orientation b Wnt1-cre; $\beta$-cat ${ }^{f \times / f x}$ e17.5 cryosection, coronal orientation $\mathbf{c} \& \mathbf{e}$ Wild type e18.5 paraffin section, coronal orientation. Boxed area in $\mathbf{c}$ is magnified in $\mathbf{e} . \mathbf{d} \& \mathbf{f}$ PO-cre; $\beta$-cat ${ }^{f \times f f x}$ e18.5 paraffin section, coronal orientation. Boxed area in $\mathbf{d}$ is magnified in $\mathbf{f}$. Blood cells are autofluorescent (pink). $\mathbf{g}$ Wild type e14.5 paraffin section, sagittal orientation. h P0-cre; $\beta$-cat ${ }^{f(f x}$ e14.5 paraffin section, sagittal orientation. i \& $\mathbf{j}$ Immunostaining for PDGFR (green), counterstained with DAPI (blue) on e17.5 paraffin, coronal sections. i Wild type j PO-cre; $\beta$-cat ${ }^{f y f x}$, blood cells are autofluorescent (pink). All scale bars equal $100 \mu \mathrm{m}$ 
Table 1 Summary of pituitary phenotypes when $\beta$-catenin is deleted with specific transgenic cre lines

\begin{tabular}{|c|c|c|c|c|}
\hline \multirow[b]{2}{*}{ Cre transgene } & \multicolumn{4}{|c|}{ Efficiency of $\beta$-catenin deletion in pituitary tissues } \\
\hline & Neural crest & Ventral diencephalon & Rathke's pouch & Pituitary phenotype \\
\hline Wnt1-cre & Complete & Sporadic & None & Dysmorphic Rathke's pouch and dilated vasculature \\
\hline Po-cre & Complete & None & Sporadic & Normal pituitary morphology and dilated vasculature \\
\hline Shh-cre & None & Sporadic & None & No pituitary phenotype \\
\hline
\end{tabular}

expression between the Wnt1-cre and the PO-cre is the expression of the Wnt1-cre in the midbrain. Our Wnt1-cre fate mapping studies demonstrate that the Wnt1-cre is also active in the posterior diencephalon. When $\beta$-catenin is deleted in the midbrain and posterior diencephalon the patterning of the entire ventral diencephalon is shifted rostrally, including the pituitary organizer, resulting in a dysmorphic Rathke's pouch. Previous studies have demonstrated that loss of Wnt1 or $\beta$-catenin in the mesencephalon causes a loss of midbrain identity and expansion of the hindbrain $[19,58,59]$. Wnt1 plays a critical role in establishing the isthmic organizer at the boundary between the between the midbrain and hindbrain [60]. Initial characterization of $\mathrm{Wnt1}^{-/-}$embryos did not identify a disruption in forebrain patterning. Examination of images in a previous characterization of $\mathrm{Wnt1}^{-/-}$embryos [59], suggests that Rathke's pouch is expanded in these embryos. Our data indicates that canonical WNT signaling is not only necessary for midbrain-hindbrain boundary formation, but also proper patterning of the ventral diencephalon.

In comparison to the ectodermal structures of the pituitary gland, very little is known about the contributions of the head mesenchyme to pituitary development. Chick explant studies demonstrate a permissive role of mesenchyme in pituitary cell specification, and a potential inductive role of the notochord in Rathke's pouch formation [8]. A mesenchymal signaling component is also supported by genetic studies in mice, where loss of Foxd1 in the mesenchyme results in an increase in pituitary anterior lobe cell number and a decrease in $\mathrm{LH} \beta$ expression [12]. It is not known what the actual mesodermal signal is that regulates pituitary development. The BMP antagonist CHORDIN is expressed in the prechordal mesoderm of mouse embryos, adjacent to the caudal side of Rathke's pouch [11]. The prechordal plate also expresses NOGGIN, and mice that are $\mathrm{Chrd}^{-/-}$; $\mathrm{Nog}^{+/-}$develop holoprosencephaly, indicative of midline patterning defects [61]. The $\mathrm{Chrd}^{-1-}$; $\mathrm{Nog}^{+/-}$ embryos do not express $N k \times 2.1$ in the ventral diencephalon, which leads to a loss of $F g f 8$ expression in the pituitary organizer and loss of Rathke's pouch [61]. These results demonstrate that the prechordal plate is necessary for establishing the pituitary organizer in the ventral diencephalon, which then induces Rathke's pouch. Direct effects of prechordal plate signaling on development of the pituitary anterior lobe are unknown.
To begin determining what functions the head mesenchyme might play in pituitary organogenesis, we fate mapped the neural crest derivatives near the pituitary gland. Our results unequivocally demonstrate that the neural crest produce the head mesenchyme on the rostral side of Rathke's pouch, and form a sharp boundary with definitive mesoderm on the caudal side of Rathke's pouch. While this boundary has been observed surrounding the eye, our results refine the position of the boundary in relation to the pituitary gland with a sharp demarcation occurring at the site of Rathke's pouch invagination [24]. It is intriguing to speculate that Rathke's pouch may provide guidance cues to neural crest cell migration. Characterization of the embryonic pituitary transcriptome identified 74 genes with gene ontology (GO) terms related to cell adhesion and migration, including genes with known roles in neural crest migration [62]. Analysis of these candidate genes may reveal differential expression within Rathke's pouch necessary for directing migrating neural crest cells to the rostral side.

A critical aspect of pituitary development is the delamination of cells from the tightly packed epithelium at the ventral side of Rathke's pouch, in a rostral direction, as they take on the shape typical of glandular cells, and form the rudimentary anterior lobe. This commences at approximately e12.5 and continues through gestation. Some neural crest derived mesenchyme cells invade the forming anterior lobe at e14.5. This is the same time that vascular invasion is initiated [63-65]. Indeed, at later stages of pituitary development the neural crest derived mesenchyme exhibits a pattern reminiscent of vascular tissue. In the vertebrate head, pericytes, regulatory cells which wrap around endothelial cells, are derived from the neural crest $[17,18]$. The neural crest cells invading the anterior lobe are likely forming the pericytes of the pituitary gland. The vasculature of both Wnt1-cre; $\beta$-cat ${ }^{f x / f x}$ and PO-cre; $\beta$-cat ${ }^{f x / f x}$ embryos is dysmorphic and dilated, which is attributable to the lack of regulatory pericytes, as marked by PDGFR $\beta$. Dilated and leaky vasculature results when pericytes are not recruited to the endothelial cells $[49,50]$. The vasculature of the Wnt1-cre; $\beta$-cat $f^{f x / f x}$ and PO-cre; $\beta$-cat $f^{f x / f x}$ pituitaries recapitulates this phenotype and demonstrates a requirement for neural crest derived pericytes in pituitary vasculature formation.

Neither the Wnt1-cre; $\beta$-cat $f^{f x / f x}$ or P0-cre; $\beta$-cat $t^{f x / f x}$ embryos display a disruption in pituitary anterior lobe 
cell specification. Therefore, the neural crest derived head mesenchyme is not necessary for normal anterior lobe cell specification. The axial mesoderm on the caudal side of Rathke's pouch is a rich source for developmental signals, which are known to pattern surrounding tissues, including the neural tube and paraxial mesoderm. Rathke's pouch sits at a dynamic site at the interface of definitive mesoderm, neural crest, neural ectoderm, and oral ectoderm. Determining the precise molecular mechanisms that each of these tissues plays in pituitary organogenesis in mouse and other vertebrate model systems will help in determining how this vertebrate specific organ may have evolved.

\section{Conclusions}

Using both the Wnt1-cre and the P0-cre to lineage trace the neural crest, we determined that the mesenchyme on the rostral side of Rathke's pouch is neural crest in origin. This rostral mesenchyme contributes to the vasculature of the pituitary gland. Deletion of a conditional null allele of $\beta$-catenin in the neural crest lineage using both the Wnt1-cre and PO-cre generates mouse embryos that are deficient in neural crest cells [19]. These embryos have dysmorphic pituitary blood vessels and lack PDGFR $\beta$ labeled pericytes. The Wnt1-cre is also active in the mesencephalon, while the PO-cre is not. Loss of $\beta$ catenin in the mesencephalon causes a loss of midbrain structures [19]. In addition, we have determined that loss of $\beta$-catenin in the mesencephalon and posterior diencephalon is the likely cause of a rostral shift in the expression domain of Bmp4 and Fgf1O in the ventral diencephalon. The altered expression domain of these morphogenetic proteins results in a highly dysmorphic Rathke's pouch. Therefore, $\beta$-catenin is required in the Wnt1 expression domain, including the neural crest, for the proper specification of pituitary gland growth, development, and vascularization.

\section{Methods}

Mice

The Institutional Committee on the Use and Care of Animals for the University of Michigan and the University of South Carolina approved all experiments using mice (protocol number PRO00004640 at the University of Michigan to SAC and protocol number 2106-100665012213 at the University of South Carolina to SWD). The Wnt1-cre, Shh -cre, $\beta$-cat $t^{f x / f x}, \operatorname{Rosa}^{\text {stopLacZ }}$, and Rosa ${ }^{m T / m G}$ mice were obtained from Jackson Laboratory [19-23]. The PO-cre mice were obtained from Dr. Ken-ichi Yamamura [21]. Mice were housed in specific pathogen free conditions with automatic watering, ventilated cages, and fed ad libitum. Genotyping of mice was performed as previously reported [19-23]. Observation of copulation plugs in female mice was used to detect mating. Noon of the day the copulation plug was detected was established as e0.5.

\section{Lineage tracing}

$\beta$-Galactosidase activity from the Rosa ${ }^{\text {stopLacZ }}$ allele was detected with X-gal staining in cryosections and embryo whole mounts. For cryosections both cre positive and cre negative Rosa $a^{\text {stopLacz }}$ embryos were fixed in $4 \%$ paraformaldehyde in LacZ fix for $15 \mathrm{~min}$ on ice, washed with LacZ wash, equilibrated in $30 \%$ sucrose, and embedded in O.C.T. Compound (Tissue-Tek) in a dry ice/ethanol bath [66]. Frozen sections were cut on a cryostat at $16 \mu \mathrm{m}$, stained with X-gal, and counterstained with Neutral Red [66]. The skin and skull were removed from cre positive and cre negative Rosa ${ }^{\text {stopLacz }}$ embryo whole mounts to allow penetration of X-gal stain. Tissues were fixed for $30 \mathrm{~min}$ in $4 \%$ paraformaldehyde in LacZ fix at $4 \mathrm{C}$, washed three times for $30 \mathrm{~min}$ in LacZ wash, and stained with $\mathrm{X}$-gal stain overnight at $37 \mathrm{C}$. The pituitary was isolated following X-gal staining and photographed on a Leica M125 microscope with a color camera. Fluorescent emission from tdTomato and eGFP was visualized using cre positive and cre negative $\operatorname{Rosa}^{m T / m G}$ embryos on a Leica M125 microscope with fluorescence capabilities and photographed using a Retiga 2000R digital camera.

\section{Histology, immunohistochemistry, and RNA in situ hybridization}

Embryos were fixed overnight in $4 \%$ paraformaldehyde in phosphate buffered saline (PBS) at $4 \mathrm{C}$, washed and dehydrated, embedded in paraffin, and sectioned at $6 \mu \mathrm{m}$ [66]. Select sections chosen for histology were stained with hematoxylin and eosin [66].

LHX3 immunofluorescence was performed as previously reported, using a primary antibody dilution of 1:1000 (Developmental Studies Hybridoma Bank, University of Iowa, Iowa City, IA) [30]. Immunofluorescence for $\beta$-CATENIN (1:1000, BD Bioscience), CD31 (1:100, PECAM, Thermo Scientific), PDGFR $\beta$ (1:100, R\&D Systems), OTX2 (1:1000, Abcam), and LEF1 (1:500, Santa Cruz Biotechnology) was performed on paraffin sections. Select sections were processed through Xylene, $100 \%$ ethanol, $95 \%$ ethanol, and PBS, and boiled in $10 \mathrm{mM}$ citric acid for $10 \mathrm{~min}$. Slides used for PECAM, OTX2, and LEF1immunohistochemistry were treated with $1.5 \%$ $\mathrm{H}_{2} \mathrm{O}_{2}$ in $50 \%$ methanol for 20 min. All slides were treated with blocking solution from Perkin-Elmer TSA Tyramide Signal Amplification (TSA) kits before incubating with primary antibodies overnight at $4 \mathrm{C}$. Species appropriate biotinylated secondary antibodies were used (Jackson ImmunoResearch Laboratories), followed by streptavidin-488 (Jackson ImmunoResearch Laboratories) for PDGFR $\beta$ and $\beta$-CATENIN or streptavidin- 
horseradish peroxidase for PECAM, OTX2, and LEF1. PECAM, OTX2, and LEF1 slides were treated with TSAFluorescein (Perkin-Elmer, TSA Plus Fluorescein System). A different PECAM antibody (BD Bioscience) and procedure was used for Fig. $8 \mathrm{a}$ and $\mathrm{b}$, which was performed on cyrosections as previously reported [67]. Antibodies for the pituitary hormones were obtained from the National Hormone \& Peptide Program, and the immunohistochemistry was performed as previously reported, and counterstained with methyl green [68].

RNA in situ hybridization was performed as previously reported for Six6, Bmp4, and Fgf10 [9, 28, 69].

\section{Ethics approval}

The Institutional Committee on the Use and Care of Animals for the University of Michigan and the University of South Carolina approved all experiments using mice (protocol number PRO00004640 at the University of Michigan to SAC and protocol number 2106-100665012213 at the University of South Carolina to SWD).

\section{Consent for publication \\ Not applicable.}

\section{Availability of data and material}

The data supporting the results of this manuscript are included in the body of the manuscript and as supplemental data.

\section{Additional files}

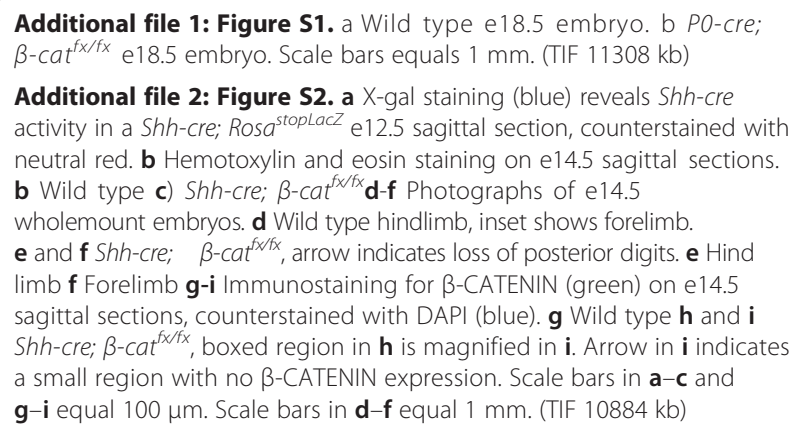

\section{Abbreviations}

e8.5: embryonic day of development 8.5; DAPI: 4',6-diamidino-2-phenylindole; GH: growth hormone; GO: gene ontology; LH: luteinizing hormone; PBS: phosphate buffered saline; POMC: proopiomelanocortin; Rosa ${ }^{m T /}$

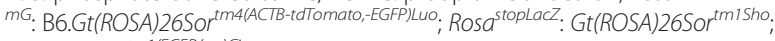

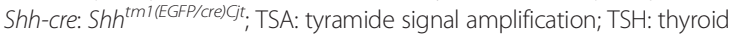

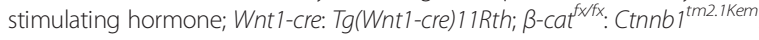

\section{Competing interests}

The authors declare that they have no competing interests.

\section{Authors' contributions}

SWD designed and conducted experiments, analyzed and interpreted data, and drafted the manuscript. AHM, JLK, ALZ, and PJG conducted experiments and revised the manuscript. KY provided the PO-cre line and revised the manuscript. SAC designed experiments, interpreted data, and revised the manuscript. All authors have read and approved the manuscript.

\section{Acknowledgements}

We would like to thank Tatiana Fiordelisio and Patrice Mollard for communicating results of their experiments ahead of publication and the sharing of experimental procedures.

\section{Funding}

Funding was provided by the National Institutes of Health - National Institute of Child Health and Human Development (R01-HD034283 and R01HD030428 to SAC), the National Institutes of Health - National Eye Institute (R01-014126 to PJG), and the University of South Carolina (start-up funds to SWD)

The funding sources did not contribute to the writing or submission of the manuscript.

\section{Author details}

'Department of Biological Sciences, University of South Carolina, 715 Sumter St. CLS room 401, Columbia, SC 29208, USA. ²Department of Human Genetics, University of Michigan, Ann Arbor, Ml 48109, USA. ${ }^{3}$ Department of Ophthalmology and Visual Sciences, University of Michigan, Ann Arbor, MI 48105, USA. ${ }^{4}$ Institute of Resource Development and Analysis, Kumamoto University, Kumamoto 860-0811, Japan. ${ }^{5}$ Present address: Department of Genetics, University of Pennsylvania, Philadelphia, PA 19104, USA.

Received: 26 January 2016 Accepted: 10 May 2016

Published online: 16 May 2016

\section{References}

1. Glenn Northcutt R. The new head hypothesis revisited. J Exp Zool B Mol Dev Evol. 2005;304(4):274-97.

2. Northcutt RG, Gans $C$. The genesis of neural crest and epidermal placodes: a reinterpretation of vertebrate origins. Q Rev Biol. 1983;58(1):1-28.

3. Steventon B, Mayor R, Streit A. Neural crest and placode interaction during the development of the cranial sensory system. Dev Biol. 2014:389(1):28-38.

4. Noden DM, Trainor PA. Relations and interactions between cranial mesoderm and neural crest populations. J Anat. 2005;207(5):575-601.

5. Rizzoti K, Lovell-Badge R. Early development of the pituitary gland: induction and shaping of Rathke's pouch. Rev Endocr Metab Disord. 2005;6(3):161-72.

6. Davis SW, Ellsworth BS, Perez Millan MI, Gergics P, Schade V, Foyouzi N, Brinkmeier ML, Mortensen AH, Camper SA. Pituitary gland development and disease: from stem cell to hormone production. Curr Top Dev Biol. 2013:106:1-47.

7. Sanchez-Arrones L, Ferran JL, Hidalgo-Sanchez M, Puelles L. Origin and early development of the chicken adenohypophysis. Front Neuroanat. 2015;9:7.

8. Gleiberman AS, Fedtsova NG, Rosenfeld MG. Tissue interactions in the induction of anterior pituitary: role of the ventral diencephalon, mesenchyme, and notochord. Dev Biol. 1999;213(2):340-53.

9. Davis SW, Camper SA. Noggin regulates Bmp4 activity during pituitary induction. Dev Biol. 2007;305(1):145-60.

10. Ericson J, Norlin S, Jessell TM, Edlund T. Integrated FGF and BMP signaling controls the progression of progenitor cell differentiation and the emergence of pattern in the embryonic anterior pituitary. Development. 1998;125(6):1005-15.

11. Treier M, Gleiberman AS, O'Connell SM, Szeto DP, McMahon JA, McMahon AP, Rosenfeld MG. Multistep signaling requirements for pituitary organogenesis in vivo. Genes Dev. 1998;12(11):1691-704.

12. Gumbel JH, Patterson EM, Owusu SA, Kabat BE, Jung DO, Simmons J, Hopkins T, Ellsworth BS. The forkhead transcription factor, Foxd1, is necessary for pituitary luteinizing hormone expression in mice. PLoS One. 2012;7(12), e52156.

13. Bronner ME, LeDouarin NM. Development and evolution of the neural crest: an overview. Dev Biol. 2012;366(1):2-9.

14. Hall BK. The neural crest as a fourth germ layer and vertebrates as quadroblastic not triploblastic. Evol Dev. 2000;2(1):3-5.

15. Buitrago-Delgado E, Nordin K, Rao A, Geary L, LaBonne C. NEURODEVELOPMENT. Shared regulatory programs suggest retention of blastula-stage potential in neural crest cells. Science. 2015;348(6241):1332-5. 
16. Couly G, Coltey P, Eichmann A, Le Douarin NM. The angiogenic potentials of the cephalic mesoderm and the origin of brain and head blood vessels. Mech Dev. 1995;53(1):97-112

17. Etchevers HC, Vincent C, Le Douarin NM, Couly GF. The cephalic neural crest provides pericytes and smooth muscle cells to all blood vessels of the face and forebrain. Development. 2001;128(7):1059-68.

18. Yamanishi E, Takahashi M, Saga Y, Osumi N. Penetration and differentiation of cephalic neural crest-derived cells in the developing mouse telencephalon. Develop Growth Differ. 2012;54(9):785-800.

19. Brault V, Moore R, Kutsch S, Ishibashi M, Rowitch DH, McMahon AP, Sommer L, Boussadia O, Kemler R. Inactivation of the beta-catenin gene by Wnt1-Cre-mediated deletion results in dramatic brain malformation and failure of craniofacial development. Development. 2001;128(8):1253-64.

20. Danielian PS, Muccino D, Rowitch DH, Michael SK, McMahon AP. Modification of gene activity in mouse embryos in utero by a tamoxifeninducible form of Cre recombinase. Curr Biol. 1998;8(24):1323-6.

21. Yamauchi Y, Abe K, Mantani A, Hitoshi Y, Suzuki M, Osuzu F, Kuratani S, Yamamura K. A novel transgenic technique that allows specific marking of the neural crest cell lineage in mice. Dev Biol. 1999;212(1):191-203.

22. Soriano P. Generalized lacZ expression with the ROSA26 Cre reporter strain. Nat Genet. 1999:21(1):70-1.

23. Muzumdar MD, Tasic B, Miyamichi K, Li L, Luo L. A global doublefluorescent Cre reporter mouse. Genesis. 2007:45(9):593-605.

24. Yoshida T, Vivatbutsiri $P$, Morriss-Kay G, Saga Y, Iseki S. Cell lineage in mammalian craniofacial mesenchyme. Mech Dev. 2008;125(9-10):797-808.

25. Khonsari RH, Seppala M, Pradel A, Dutel H, Clement G, Lebedev O, Ghafoor S, Rothova M, Tucker A, Maisey JG, et al. The buccohypophyseal canal is an ancestral vertebrate trait maintained by modulation in sonic hedgehog signaling. BMC Biol. 2013;11:27.

26. Barteczko K, Jacob M. Comparative study of shape, course, and disintegration of the rostral notochord in some vertebrates, especially humans. Anat Embryol (Berl). 1999:200(4):345-66.

27. Bazina M, Stefanovic V, Bozanic D, Saraga-Babic M. Ultrastructural and immunohistochemical characteristics of developing human pituitary gland. Acta Histochem. 2007;109(5):366-76.

28. Bellusci S, Grindley J, Emoto H, Itoh N, Hogan BL. Fibroblast growth factor 10 (FGF10) and branching morphogenesis in the embryonic mouse lung. Development. 1997;124(23):4867-78.

29. Takuma N, Sheng HZ, Furuta Y, Ward JM, Sharma K, Hogan BL, Pfaff SL, Westphal H, Kimura S, Mahon KA. Formation of Rathke's pouch requires dual induction from the diencephalon. Development. 1998;125(23):4835-40.

30. Brinkmeier ML, Potok MA, Davis SW, Camper SA. TCF4 deficiency expands ventral diencephalon signaling and increases induction of pituitary progenitors. Dev Biol. 2007;311(2):396-407.

31. Potok MA, Cha KB, Hunt A, Brinkmeier ML, Leitges M, Kispert A, Camper SA. WNT signaling affects gene expression in the ventral diencephalon and pituitary gland growth. Dev Dyn. 2008;237(4):1006-20.

32. Rizzoti K, Brunelli S, Carmignac D, Thomas PQ, Robinson IC, Lovell-Badge R. SOX3 is required during the formation of the hypothalamo-pituitary axis. Nat Genet. 2004;36(3):247-55.

33. Paek H, Hwang JY, Zukin RS, Hebert JM. beta-Catenin-dependent FGF signaling sustains cell survival in the anterior embryonic head by countering Smad4. Dev Cell. 2011;20(5):689-99.

34. Olson LE, Tollkuhn J, Scafoglio C, Krones A, Zhang J, Ohgi KA, Wu W, Taketo MM, Kemler R, Grosschedl R, et al. Homeodomain-mediated beta-catenindependent switching events dictate cell-lineage determination. Cell. 2006; 125(3):593-605.

35. Salisbury TB, Binder AK, Grammer JC, Nilson JH. Maximal activity of the luteinizing hormone beta-subunit gene requires beta-catenin. Mol Endocrinol. 2007:21(4):963-71.

36. Skowronska-Krawczyk D, Ma Q, Schwartz M, Scully K, Li W, Liu Z, Taylor H, Tollkuhn J, Ohgi KA, Notani D, et al. Required enhancer-matrin-3 network interactions for a homeodomain transcription program. Nature. 2014; 514(7521):257-61.

37. Kioussi C, Briata P, Baek SH, Rose DW, Hamblet NS, Herman T, Ohgi KA, Lin C, Gleiberman A, Wang J, et al. Identification of a Wnt/Dvl/beta-Catenin - > Pitx2 pathway mediating cell-type-specific proliferation during development. Cell. 2002:111(5):673-85.

38. Harfe BD, Scherz PJ, Nissim S, Tian H, McMahon AP, Tabin CJ. Evidence for an expansion-based temporal Shh gradient in specifying vertebrate digit identities. Cell. 2004;118(4):517-28.
39. Kawakami Y, Marti M, Kawakami H, Itou J, Quach T, Johnson A, Sahara S, O'Leary DD, Nakagawa Y, Lewandoski M, et al. Islet1-mediated activation of the beta-catenin pathway is necessary for hindlimb initiation in mice. Development. 2011;138(20):4465-73.

40. Bao J, Ma HY, Schuster A, Lin YM, Yan W. Incomplete cre-mediated excision leads to phenotypic differences between Stra8-iCre; Mov10l1(lox/lox) and Stra8-iCre; Mov10l1(lox/Delta) mice. Genesis. 2013;51(7):481-90.

41. Hebert JM, McConnell SK. Targeting of cre to the Foxg1 (BF-1) locus mediates loxP recombination in the telencephalon and other developing head structures. Dev Biol. 2000;222(2):296-306.

42. Heffner CS, Herbert Pratt C, Babiuk RP, Sharma Y, Rockwood SF, Donahue LR, Eppig JT, Murray SA. Supporting conditional mouse mutagenesis with a comprehensive cre characterization resource. Nat Commun. 2012;3:1218.

43. Turlo KA, Gallaher SD, Vora R, Laski FA, Iruela-Arispe ML. When Cre-mediated recombination in mice does not result in protein loss. Genetics. 2010;186(3):959-67.

44. Simeone A, Acampora D, Gulisano M, Stornaiuolo A, Boncinelli E. Nested expression domains of four homeobox genes in developing rostral brain. Nature. 1992:358(6388):687-90.

45. Martinez-Barbera JP, Signore M, Boyl PP, Puelles E, Acampora D, Gogoi R, Schubert F, Lumsden A, Simeone A. Regionalisation of anterior neuroectoderm and its competence in responding to forebrain and midbrain inducing activities depend on mutual antagonism between OTX2 and GBX2. Development. 2001;128(23):4789-800.

46. Acampora D, Avantaggiato V, Tuorto F, Simeone A. Genetic control of brain morphogenesis through Otx gene dosage requirement. Development. 1997; 124(18):3639-50.

47. Mortensen AH, Schade V, Lamonerie T, Camper SA. Deletion of OTX2 in neural ectoderm delays anterior pituitary development. Hum Mol Genet. 2015:24(4):939-53.

48. Shimogori T, Lee DA, Miranda-Angulo A, Yang $Y$, Wang $H$, Jiang L, Yoshida AC, Kataoka A, Mashiko H, Avetisyan M, et al. A genomic atlas of mouse hypothalamic development. Nat Neurosci. 2010;13(6):767-75.

49. Lindahl P, Hellstrom M, Kalen M, Karlsson L, Pekny M, Pekna M, Soriano P, Betsholtz C. Paracrine PDGF-B/PDGF-Rbeta signaling controls mesangial cell development in kidney glomeruli. Development. 1998;125(17):3313-22.

50. Lindahl P, Johansson BR, Leveen P, Betsholtz C. Pericyte loss and microaneurysm formation in PDGF-B-deficient mice. Science. 1997; 277(5323):242-5.

51. Soriano P. Abnormal kidney development and hematological disorders in PDGF beta-receptor mutant mice. Genes Dev. 1994;8(16):1888-96.

52. Aujla PK, Bogdanovic V, Naratadam GT, Raetzman LT. Persistent expression of activated Notch in the developing hypothalamus affects survival of pituitary progenitors and alters pituitary structure. Dev Dyn. 2015;244(8):921-34

53. Aguiar DP, Sghari S, Creuzet S. The facial neural crest controls fore- and midbrain patterning by regulating Foxg1 expression through Smad1 activity. Development. 2014;141(12):2494-505.

54. Creuzet SE, Martinez S, Le Douarin NM. The cephalic neural crest exerts a critical effect on forebrain and midbrain development. Proc Natl Acad Sci U S A. 2006:103(38):14033-8.

55. Garcez RC, Le Douarin NM, Creuzet SE. Combinatorial activity of Six1-2-4 genes in cephalic neural crest cells controls craniofacial and brain development. Cell Mol Life Sci. 2014;71(11):2149-64.

56. Cha KB, Douglas KR, Potok MA, Liang H, Jones SN, Camper SA. WNT5A signaling affects pituitary gland shape. Mech Dev. 2004;121(2):183-94.

57. van Amerongen $\mathrm{R}$, Fuerer $\mathrm{C}$, Mizutani M, Nusse R. Wnt5a can both activate and repress Wnt/beta-catenin signaling during mouse embryonic development. Dev Biol. 2012;369(1):101-14.

58. McMahon AP, Bradley A. The Wnt-1 (int-1) proto-oncogene is required for development of a large region of the mouse brain. Cell. 1990;62(6):1073-85.

59. McMahon AP, Joyner AL, Bradley A, McMahon JA. The midbrain-hindbrain phenotype of Wnt-1-/Wnt-1- mice results from stepwise deletion of engrailed-expressing cells by 9.5 days postcoitum. Cell. 1992;69(4):581-95.

60. Nakamura H, Katahira T, Matsunaga E, Sato T. Isthmus organizer for midbrain and hindbrain development. Brain Res Brain Res Rev. 2005:49(2):120-6.

61. Anderson RM, Lawrence AR, Stottmann RW, Bachiller D, Klingensmith J. Chordin and noggin promote organizing centers of forebrain development in the mouse. Development. 2002;129(21):4975-87. 
62. Davis SW, Potok MA, Brinkmeier ML, Carninci P, Lyons RH, MacDonald JW, Fleming MT, Mortensen AH, Egashira N, Ghosh D, et al. Genetics, gene expression and bioinformatics of the pituitary gland. Horm Res. 2009;71 Suppl 2:101-15.

63. Hashimoto $\mathrm{H}$, Ishikawa $\mathrm{H}$, Kusakabe M. Three-dimensional analysis of the developing pituitary gland in the mouse. Dev Dyn. 1998;212(1):157-66.

64. Sasaki F, Iwama Y. Correlation of spatial differences in concentrations of prolactin and growth hormone cells with vascular pattern in the female mouse adenohypophysis. Endocrinology. 1988;122(4):1622-30.

65. Szabo K. Origin of the adenohypophyseal vessels in the rat. J Anat. 1987; 154:229-35.

66. Hogan B, Beddington R, Costantini F, Lacey E. Manipulating the mouse embryo: a laboratory manual. Plainview, New York: Cold Spring Harbor Laboratory Press; 1994.

67. Ward RD, Stone BM, Raetzman LT, Camper SA. Cell proliferation and vascularization in mouse models of pituitary hormone deficiency. Mol Endocrinol. 2006;20(6):1378-90.

68. Kendall SK, Gordon DF, Birkmeier TS, Petrey D, Sarapura VD, O'Shea KS, Wood WM, Lloyd RV, Ridgway EC, Camper SA. Enhancer-mediated high level expression of mouse pituitary glycoprotein hormone a-subunit transgene in thyrotropes, gonadotropes, and developing pituitary gland. Mol Endocrinol. 1994:8:1420-33.

69. Jones CM, Lyons KM, Hogan BL. Involvement of Bone Morphogenetic Protein-4 (BMP-4) and Vgr-1 in morphogenesis and neurogenesis in the mouse. Development. 1991;111(2):531-42.

\section{Submit your next manuscript to BioMed Central} and we will help you at every step:

- We accept pre-submission inquiries

- Our selector tool helps you to find the most relevant journal

- We provide round the clock customer support

- Convenient online submission

- Thorough peer review

- Inclusion in PubMed and all major indexing services

- Maximum visibility for your research

Submit your manuscript at www.biomedcentral.com/submit 